\title{
COMPARATIVE STUDY BETWEEN METHODOLOGIES USED FOR DETERMINATION OF THE TOTAL HARDNESS IN AQUEOUS MATRICES.
}

\author{
FERNANDES, Natasha L. ${ }^{*} ;$ BARRETO, Natacha M. B. ${ }^{2}$; MACHADO, Alessandro C. ${ }^{3}$; ROCHA, \\ Genilda P. ${ }^{4}$. \\ 1,2,3,4 Centro de Tecnologia SENAI Ambiental/ Sistema FIRJAN, Rua Morais e Silva, 53, bloco 09, \\ cep: 20271-030, Rio de Janeiro - RJ, Brasil \\ (fone: +55 $2139786110 ;+552139786112$ ) \\ * Natasha Leite Fernandes \\ e-mail: nfernandes@firjan.org.br
}

Received 12 April 2015; received in revised form 30 June 2015; accepted 2 July 2015

\section{RESUMO}

A dureza afeta a qualidade da água, tornando-a indesejável ao consumo e inadequada à utilização em processos industriais. Este trabalho compara o método titulométrico com o método espectrométrico para determinação da dureza em matrizes aquosas, avaliando as vantagens e desvantagens da aplicação de cada um deles.

Palavras-chave: Dureza total, Espectrometria, Comparação de métodos.

\begin{abstract}
Hardness affects the quality of water, making it unsuitable for human consumption and undesirable for the use in industrial processes. This paper compares the titrimetric method with the spectrometric method for the determination of hardness in aqueous matrices, evaluating the advantages and disadvantages of each application.
\end{abstract}

Keywords: Total Hardness, Spectrometry, Comparative Method.

\section{INTRODUÇÃO}

A dureza da água pode ser originada de forma natural (dissolução de rochas calcárias, ricas em cálcio e magnésio) ou de forma antropogênica (despejos industriais). Os íons $\mathrm{Ca} 2+$ e Mg2+ em condições de supersaturação reagem com os ânions da água formando precipitados. São os maiores contribuintes na dureza, principalmente quando associados aos carbonatos e/ou bicarbonatos. Desta forma, as águas subterrâneas apresentam dureza mais elevada do que as superficiais.

Este parâmetro é característico para o controle da qualidade de águas destinadas ao abastecimento doméstico e industrial. No âmbito doméstico, não há evidências de problemas sanitários. Todavia, a elevada dureza pode afetar as propriedades organolépticas da água, tornando-a inadequada ao consumo humano; diminuir a formação de espuma, implicando em um consumo maior de xampus e sabões; pode causar efeitos laxativos em alguns casos. $\mathrm{Na}$ área industrial, as concentrações elevadas podem ocasionar incrustações nas tubulações de água quente, caldeiras e aquecedores, em função da precipitação dos cátions em altas temperaturas, podendo provocar explosões.

No Brasil, só há limite para dureza total em água destinada ao consumo humano, estabelecido pela Portaria MS 2914, de 12 de Dezembro de 2011, sendo o valor máximo 
permitido de $500 \mathrm{mg} / \mathrm{L}$. No entanto, é realizado o monitoramento frequente em águas para controle de processos, efluentes, águas residuais $\mathrm{e}$ caracterização de corpos d'água receptores (rios e lagos).

Visando a otimização das análises ambientais do laboratório do Centro de Tecnologia SENAI Ambiental, propusemos comparar duas metodologias para a determinação da dureza total em amostras aquosas: análise pelo método normalizado de titulação por complexação com ácido etilenodiaminotetracetico (EDTA) e análise de cálcio $(\mathrm{Ca})$ e magnésio $(\mathrm{Mg})$ por espectrometria de emissão ótica por plasma indutivamente acoplado (ICP-OES), esta última, sendo metodologia já desenvolvida e validada pelo laboratório. Avaliar as vantagens e desvantagens na aplicabilidade desses métodos na rotina de trabalho do laboratório.

\section{MATERIAL E MÉTODOS:}

\subsection{Método titulométrico (método 1)}

O método utilizado é o Standard Methods 2340 C, que consiste em uma titulação complexométrica em meio tamponado, usando o EDTA como titulante e negro de eriocromo T, como indicador. O cálcio e o magnésio serão preferencialmente complexados. Depois que o EDTA tenha complexado todo $\mathrm{o}$ cálcio e magnésio, a solução se tornará azul, indicando a formação do complexo entre o indicador e o EDTA. Este é o ponto final da titulação.

\subsection{Método espectrométrico (método 2)}

O método para determinação de cálcio e magnésio tem como base no USEPA 200.7 (United States Environmental Protection Agency) e o Standard Methods 2340 B. Para esta metodologia, a dureza é determinada a partir da conversão do teor de cálcio e magnésio em carbonato de cálcio. A técnica de ICP-OES se baseia na medida de emissão de fótons proveniente do decaimento de átomos e íons excitados pelo argônio. A medida do comprimento de onda emitido possibilita a obtenção de dados qualitativos e a intensidade da radiação emitida permite a quantificação dos elementos químicos de interesse.

\subsubsection{Preparo e leitura das amostras}

As amostras límpidas são lidas diretamente no equipamento $e$ as que apresentam particulados, são digeridas previamente, com ácido nítrico P.A à $80^{\circ} \mathrm{C}$ por 2 horas.

A leitura das amostras é realizada segundo as condições descritas na Tabela 1.

\subsubsection{Expressão dos resultados}

Dureza Total $\left(\mathrm{CaCO}_{3}\right)=[(\mathrm{Ca}(\mathrm{mg} / \mathrm{L}) \times 2,497]+$ [(Mg $(\mathrm{mg} / \mathrm{L}) \times 4,118]$

Onde:

2,497= fator de conversão de teor de cálcio em carbonato de cálcio

$4,118=$ fator de conversão de teor de magnésio em carbonato de cálcio

$\mathrm{Ca}=$ Concentração de cálcio obtida em $\mathrm{mg} / \mathrm{L}$ $\mathrm{Mg}=$ Concentração de magnésio obtida em mg/L

\subsection{Validação (método 2)}

Foi realizada validação para o método 2 , através da determinação de cálcio e magnésio, baseada no documento DOC-CGCRE-008

rev.04, do Inmetro, onde foram avaliados os seguintes parâmetros:

- Seletividade: testou-se a igualdade das inclinações das curvas analíticas com e sem matriz, aplicando-se 0 teste $t$ student, com intervalo de $95 \%$ de confiança;

- Linearidade: fez-se um gráfico de resíduos da curva analítica sem matriz para verificar possíveis tendências e aplicou-se 0 teste de Cochran para avaliar a homocedasticidade da curva;

- Valores aberrantes: verificou-se a existência de valores aberrantes ao longo da faixa de trabalho, através do teste de Grubbs, para o nível de confiança de 95\%;

- Limite de Quantificação (LQ): adotou-se o primeiro ponto da curva analítica para expressar o limite, calculando-se a repetibilidade e recuperação;

- Limite de Detecção (LD): para obtê-lo, dividiu-se o valor do LQ por 3;

PERIÓDICO TCHÊ QUÍMICA • www.periodico.tchequimica.com • Vol. 12 N. 24 
- Recuperação: foi realizado um teste de recuperação do padrão, em triplicata. Calculou-se o erro, o erro médio e a recuperação da amostra analisada;

- Repetibilidade: foi calculado para três níveis de concentração da curva analítica, realizada em triplicata, a média, o desvio padrão e o desvio padrão relativo de cada concentração;

- Precisão intermediária entre analistas: dois analistas prepararam e analisaram um padrão dentro da faixa de trabalho, em triplicata. Calculou-se a média, o desvio padrão e a variância, comparandose os resultados dos dois analistas através de teste $\mathrm{F}$, com intervalo de $95 \%$ de confiança;

- Reprodutibilidade: verificou-se a reprodutibilidade mediante os resultados de participação de programa interlaboratorial.

Nota: Ao realizar a validação da metodologia de cálcio e magnésio, a de dureza total também é validada, uma vez que seu resultado é obtido por fator de conversão.

\subsection{Comparação das Metodologias Estudadas}

No estudo comparativo das metodologias, foram preparadas cinco replicatas de brancos fortificados de laboratório (BFL), com material de referência certificado de cálcio e magnésio (marca Sigma Aldrich), nas concentrações de $6,62 \mathrm{mg} / \mathrm{L}, 33,08 \mathrm{mg} / \mathrm{L}$ e $62,15 \mathrm{mg} / \mathrm{L}$, a fim de serem analisadas em ambas as técnicas. $\mathrm{Na}$ avaliação da precisão entre os métodos estudados, foi utilizado o teste estatístico $\mathrm{F}$ de Snedecor.

\section{RESULTADOS E DISCUSSÃO:}

\subsection{Validação (método 2)}

Os resultados obtidos para os parâmetros de validação são demonstrados nas tabelas 2 e 3.

Através dos testes estatísticos, o método mostrou ser seletivo, comprovando que a matriz não interfere na concentração obtida. A faixa de trabalho apresentou linearidade satisfatória, livre de tendências e sem valores aberrantes. Todos os níveis de concentração estudados apresentaram desvio padrão relativo menor que $10 \%$, indicando boa repetibilidade entre as replicatas. As concentrações mantiveram recuperação aceitável, em torno de $2 \%$ de erro. Os limites de detecção e quantificação foram mais que satisfatórios, estando bem abaixo do limite estabelecido pela norma. Não houve variação entre os analistas, podendo a análise ser executada por ambos. O método apresentou excelente desempenho em todos os interlaboratoriais realizados, indicando proficiência ao ser comparado a outros laboratórios. Os resultados deverão ser apresentados de maneira concisa juntamente com uma breve discussão. Se possível, comparar os resultados no contexto de outros trabalhos já realizados e previsões teóricas.

\subsection{Avaliação estatística para a comparação das metodologias estudadas.}

$\mathrm{Na}$ Tabela 4 , constam os dados obtidos para a avaliação da equivalência dos resultados.

Observou-se que, para a concentração de $6,62 \mathrm{mg} / \mathrm{L}$, os resultados obtidos nos dois métodos não são estatisticamente iguais, uma vez que o $F_{\text {calculado }}$ foi maior que o $F_{\text {tabelado. Isto se }}$ deve a maior dispersão das replicatas do método titulométrico, em comparação ao método espectrométrico. Um fator de contribuição, é a variação de volume gasto de EDTA na titulação entre as replicatas de $\pm 0,01 \mathrm{~mL}$, acarretando em um desvio padrão de aproximadamente 0,10 $\mathrm{mg} / \mathrm{L}$, sendo crítico para concentrações mais baixas. Para os outros níveis de concentração mais altos, o desvio padrão não é crítico, apresentando equivalência entre os resultados.

O estudo comprovou as seguintes desvantagens para determinação de dureza total pela técnica de titulação:

1. Necessidade de grandes volumes de amostra, principalmente quando se quer atingir limites mais baixos;

2. Consumo elevado de reagentes;

3. Tempo de análise longo;

4. Limita-se a determinar a dureza total, necessitando de outro procedimento titulométrico para a determinação da dureza de cálcio e dureza de magnésio. 
5. Grande probabilidade de ocorrer erros relacionados aos materiais utilizados $\mathrm{e}$, inclusive, do próprio analista.

Já a técnica espectrométrica, reverte todas essas desvantagens, além de proporcionar os resultados de dureza de cálcio e magnésio individualmente e com maior confiabilidade metrológica.

\section{CONCLUSÕES:}

De acordo com os testes realizados, pode-se considerar que a técnica por ICP-OES é aplicável à determinação de dureza total em matrizes aquosas. Para o laboratório do CTS Ambiental, que já realiza e mantém estrutura para analise de metais, a substituição da técnica titulométrica pela técnica espectrométrica demonstrou ser mais vantajosa, além de ter maior sensibilidade e quantificar simultaneamente o teor das durezas de cálcio e magnésio em um mesmo procedimento analítico.

\section{AGRADECIMENTOS:}

Os autores agradecem ao Sistema Firjan pelo estímulo à produção científica e a seus colaboradores, além do apoio do projeto RESAG.

\section{REFERÊNCIAS:}

1. EATON, A. D., CLESCERI, L. S., GREENBERG, A. E. Standard Methods for the Examination of Water and Wastewater. APHA, AWWA, WEF. $22^{\mathrm{a}}$ ed. 2012. Método: $2340 \mathrm{~B} / 2340 \mathrm{C}$

2. USEPA 200.7: Determination of Metals and Trace Elements in Water and Waste by Inductively Coupled Plasma Atomic Emission Spectrometry

3. INMETRO- Orientações sobre validação de métodos analíticos- DQO-CGCRE-008, revisão 04-Jul/2011.

4. Ministério da Saúde. Vigilância e controle da qualidade da água para consumo humano, Brasília, 2006, págs.49 - 50.

5. Skoog, D.A; West, D.M; Holler, F.J. \& Stanley, R.C. Fundamentos da Química Analítica, Tradução da $8^{a}$ edição norte americana. São Paulo, Ed. Thomson, 2007.

6. BRASIL. Portaria $\mathrm{n}^{\circ} 2914$ de 12 de dezembro de 2011 do Ministério da Saúde.

Tabela 1. Condições de operação do ICP-OES marca Perkin Elmer, modelo Optima 4300 DV

\begin{tabular}{c|c|c|c}
\hline Metal & Comprimento de Onda $(\mathbf{n m})$ & $\begin{array}{c}\text { Fluxo de Gás do Plasma } \\
(\text { L/min) }\end{array}$ & $\begin{array}{c}\text { Vista do } \\
\text { Plasma }\end{array}$ \\
\hline Cálcio & 317.933 & 17 & Axial \\
\hline Magnésio & 285.213 & 17 & Axial \\
\hline
\end{tabular}

Tabela 3. Resultado de participações em programas interlaboratoriais de dureza total.

\begin{tabular}{c|c|c}
\hline Mês/ano de Realização & Performance do Resultado Obtido & Z-Score \\
\hline $\mathrm{abr} / 14$ & Excelente & $-0,433$ \\
\hline $\mathrm{abr} / 14$ & Excelente & $-0,104$ \\
\hline jun/14 & Proficiente & 0,16 \\
\hline $\mathrm{jul} / 14$ & Proficiente & $-1,13$ \\
\hline
\end{tabular}

PERIÓDICO TCHÊ QUÍMICA • www.periodico.tchequimica.com • Vol. 12 N. 24 
Tabela 2 . Resultados da validação da Dureza Total pelo método espectrométrico (método 2)

\begin{tabular}{c|c|c}
\hline Parâmetros & Cálcio & Magnésio \\
\hline Seletividade & $\mathrm{T}_{\text {calc }}<\mathrm{T}_{\text {tab }}(1,698<2,055)$ & $\mathrm{T}_{\text {calc }}<\mathrm{T}_{\text {tab }}(0,311<2,055)$ \\
\hline Linearidade (R $)$ & 0,99964 & 0,99971 \\
\hline Linearidade & $\mathrm{C}_{\text {calc }}<\mathrm{C}_{\text {tab }}(0,470<0,684)$ & $\mathrm{C}_{\text {calc }}<\mathrm{C}_{\text {tab }}(0,577<0,684)$ \\
\hline Valor Aberrante & $\mathrm{G}_{\text {calc }}<\mathrm{G}_{\text {tab }}(1,154<1,156)$ & $\mathrm{G}_{\text {calc }}<\mathrm{G}_{\text {tab }}(1,135<1,156)$ \\
\hline Repetibilidade (DPR \%) & $0,93 \%$ & $0,88 \%$ \\
\hline Precisão Intermediária & $\mathrm{F}_{\text {calc }}<\mathrm{F}_{\text {tab }}(2,009<19)$ & $\mathrm{F}_{\text {calc }}<\mathrm{F}_{\text {tab }}(0,588<19)$ \\
\hline Recuperação (\%) & $100,06 \%$ & $98,43 \%$ \\
\hline Limite de detecção & $0,30 \mathrm{mg} / \mathrm{L}$ & $0,30 \mathrm{mg} / \mathrm{L}$ \\
\hline Limite de quantificação & $1,00 \mathrm{mg} / \mathrm{L}$ & $1,00 \mathrm{mg} / \mathrm{L}$ \\
\hline
\end{tabular}

Tabela 4. Dados para avaliação da equivalência dos resultados.

\begin{tabular}{|c|c|c|c|c|}
\hline $\begin{array}{c}\text { Concentração Nominal } \\
(\mathrm{mg} / \mathrm{L})\end{array}$ & $\begin{array}{l}\text { Método } 1 \\
\text { (mg/L) }\end{array}$ & $\begin{array}{l}\text { Método } 2 \\
\text { (mg/L) }\end{array}$ & $\mathbf{F}_{\text {cal }}$ & $F_{\text {tab }}$ \\
\hline \multirow{5}{*}{6,62} & 6,44 & 6,33 & \multirow{5}{*}{9,98} & \multirow{5}{*}{$4,2 \varepsilon$} \\
\hline & 6,44 & 6,37 & & \\
\hline & 6,35 & 6,39 & & \\
\hline & 6,25 & 6,39 & & \\
\hline & 6,25 & 6,40 & & \\
\hline \multirow{5}{*}{33,08} & 32,39 & 33,96 & \multirow{5}{*}{1,57} & \multirow{5}{*}{4,28} \\
\hline & 32,58 & 34,47 & & \\
\hline & 31,91 & 34,13 & & \\
\hline & 32,01 & 33,99 & & \\
\hline & 32,20 & 33,97 & & \\
\hline \multirow{5}{*}{66,15} & 63,35 & 67,29 & \multirow{5}{*}{3,71} & \multirow{5}{*}{4,28} \\
\hline & 63,35 & 67,92 & & \\
\hline & 63,35 & 67,41 & & \\
\hline & 62,88 & 67,97 & & \\
\hline & 63,16 & 67,06 & & \\
\hline
\end{tabular}

PERIÓDICO TCHÊ QUÍMICA • www.periodico.tchequimica.com • Vol. 12 N. 24.

• ISSN 1806-0374 (impresso) • ISSN 1806-9827 (CD-ROM) • ISSN 2179-0302 (meio eletrônico)

(C) 2015. Porto Alegre, RS. Brasil

The Periódico Tchê Química (ISSN: 1806-0374; 2179-0302) is an open-access journal since 2004. Journal DOI: 10.52571/PTQ. http://www.tchequimica.com. This text was introduced in this file in 2021 for compliance reasons.

OPEN ACCESS. This article is licensed under a Creative Commons Attribution 4.0 (CC BY 4.0) International License, which permits use, sharing, adaptation, distribution, and reproduction in any medium or format, as long as you give appropriate credit to the original author(s) and the source, provide a link to the Creative Commons license, and indicate if changes were made. The images or other third-party material in this article are included in the or exceeds the permitted use, you will need to obtain permission directly from the copyright holder. To view a copy of this license, visit htpp//creativecommons. 